\title{
PROCESOS MIGRATORIOS Y TRANSFORMACIONES SOCIOPRODUCTIVAS EN EL NORESTE DEL PARTIDO DE TAPALQUÉ, PROVINCIA DE BUENOS AIRES ${ }^{1}$
}

\author{
Mónica AURAND²
}

\section{Resumen}

El objetivo del artículo es presentar una aproximación a la intensificación de los procesos migratorios hacia las urbes, a partir de la década de 1960, de productores familiares ganaderos y de pobladores de las localidades rurales del noreste del Partido de Tapalqué (Provincia de Buenos Aires). Se considerarán las profundas transformaciones socioeconómicas que acompañaron tales procesos destacando el rol del Estado como así también las diversas trayectorias y estrategias familiares.

Palabras clave: procesos migratorios; políticas públicas; ganadería; éxodo rural; mercado laboral.

\begin{abstract}
The objective of this article is to introduce an approach to the intensification of the migratory processes to the cities, since the 1960s, of livestock family farmers and rural residents in the northeast of Tapalqué (Province of Buenos Aires). The deep socioeconomical transformations that accompanied those processes, emphazising the role of the State, will be considered as well as the different familiar trajectories and strategies.
\end{abstract}

Keywords: migratory processes; public policy; cattle raising; rural exodus; labour market.

\section{Resumé}

Cet article vise à enquêter sur l'intensification des processus migratoires aux villes, à partir des années 1960, des éleveurs familiaux de bétail et des habitants des localités rurales du nord-est du département de Tapalqué, dans la Provincia de Buenos Aires. Pour ce faire, je prends en compte les transformations socio-économiques profondes qui ont accompagné ces processus, et je souligne le rôle de l'État ainsi que les différents trajectoires et stratégies familiales.

Mots-clés: processus migratoires; politiques publiques; élevage; exode rural; marché du travail.

\footnotetext{
1 Una versión preliminar de este artículo se presentó en el XI Congreso Argentino de Antropología Social.

2 Becaria doctoral FFyL-UBA.
}

Fecha de recepción del artículo:Agosto 2014

Fecha de evaluación: Noviembre 2014 


\section{Introducción}

A partir de la década de 1960, se profundiza en el noreste del partido de Tapalqué (Provincia de Buenos Aires) el proceso migratorio de productores familiares ganaderos hacia las urbes. Es el objetivo de este trabajo -enmarcado en la investigación de tesis doctoral de la UBA3- efectuar una aproximación general a la cuestión, considerando las profundas transformaciones socioeconómicas que acompañaron tales procesos, destacando el rol del Estado y atendiendo a las diversas trayectorias y estrategias migratorias familiares. Lo aquí abordado constituye una muestra emblemática de las transformaciones en los ámbitos rurales en Argentina en las últimas décadas y la manera que ha impactado en los pobladores rurales.

A fin de organizar el escrito, en este mismo apartado, se explicitarán los lineamientos teóricometodológicos empleados. En segundo término, se realizará una breve contextualización sociohistórica de la región abordada. Después, se expondrán y examinarán algunas de las políticas públicas desplegadas a partir de los años sesenta en articulación con las transformaciones socioproductivas. Seguidamente, se describirán algunas de las estrategias y trayectorias migratorias familiares en la zona. Luego, se analizarán algunas de las políticas públicas tendientes a revertir los procesos migratorios rurales-urbanos. Posteriormente, se expondrán algunos de los diversos procesos participativos de los migrantes en el ámbito de origen como así también aquellos procesos migratorios de retorno. Por último, se presentarán brevemente una serie de reflexiones finales.

Procurando un acercamiento al objetivo propuesto, el procedimiento teórico-metodológico, se ha basado en el relevamiento, sistematización y análisis de material bibliográfico, estadístico ${ }^{4} \mathrm{y}$ documental relativo al proceso sociohistórico de desarrollo regional. Atendiendo a una perspectiva etnográfica, las estrategias metodológicas empleadas han sido entrevistas abiertas y en profundidad, observación participante e historias de vida entre productores familiares en actividad y retirados, pobladores residentes en la zona y emigrados, focalizados principalmente en el área noreste del Partido, como así también en la ciudad de Tapalqué y en la localidad de Cacharí (Partido de Azul).

Asimismo, y reparando en la fuerte diferenciación que realizaron los entrevistados al interior de los productores familiares (basada en la superficie de las explotaciones y su relación con la carga ganadera), se ha decidido integrar sus estratificaciones y categorizaciones; en este sentido "campos chicos" serán consideradas las explotaciones de hasta 200 ha; "campos medianos" aquellas comprendidas entre 200 y 1000 ha; y "estancias grandes" de más de 1.000 ha. Ello permitió evidenciar no sólo la heterogeneidad existente al interior de los productores familiares ganaderos sino también la existencia -como ha advertido Comas D'Argemir para su análisis de un caso español- "(...) de estrategias económicas, sociales e ideológicas dirigidas a la consecución de objetivos divergentes" (Comas D'Argemir, 1983: 82).

Para el abordaje de los procesos migratorios rurales-urbanos desplegados en la región se ha recuperado la propuesta de Lourdes Arizpe (1976), trabajando articuladamente el nivel macroestructural (los grandes procesos económicos, políticos y sociales), el nivel regional (características del lugar de origen y de destino) y el nivel micro de análisis (las motivaciones personales de los emigrantes) (Arizpe, 1976). En este sentido, los migrantes son considerados, en los términos expuestos por Devoto: “(...) como sujetos activos capaces de formular estrategias de supervivencia y readaptación

3 "Políticas agrarias y de desarrollo: estrategias de reproducción social de pequeños y medianos productores del Partido de Tapalqué, Provincia de Buenos Aires, en un contexto de transformaciones socioeconómicas y socioambientales".

$4 \quad$ Se han empleado los Censos Nacionales Agropecuarios (CNA) de 1960, 1988 y 2002. Debido a las diferencias existentes en los datos estadísticos de los censos, y con la finalidad de poder realizar una comparación intercensal, se han recuperado las propuestas metodológicas detalladas por Vidal para su abordaje (Vidal, 2007). Asimismo, hay que remarcar que, durante la realización del CNA 2002, una parte del territorio del municipio se encontraba inundado (La Nación, 2001); por lo cual sólo pudieron ser registradas 270.895,4 ha (64,9\%) de las aproximadamente 417.200 ha de superficie agraria total del Partido. Aquí se ha decidido incorporarlo ya que, a pesar de tales limitaciones, permite una aproximación cuantitativa sobre las características agropecuarias de la zona abordada. 
en contextos de cambio macroestructurales" (Devoto, 1992: 96). También resultaron valiosas aquellas perspectivas actuales que incorporan el análisis de las "cadenas migratorias" y destacan el carácter relacional y multidimensional de los movimientos migratorios (Pedone, 2010); como así también aquellas que han reparado en la participación de los migrantes en la vida económica, política y cultural del ámbito de origen (Portes, 2007; Basch, Glick Schiller y Blanc-Szanton, 1994 en Pedone, 2010).

\section{Breve contextualización sociohistórica}

El Partido de Tapalqué, se ubica en la región pampeana, en el centro geográfico de la Provincia de Buenos Aires, y limita con los partidos de Azul, Las Flores, General Alvear, Olavarría y Bolívar (ver imagen 1 y 2).

Históricamente se ha orientado a la cría extensiva de ganado (bovino y ovino) y, en menor medida, a la agricultura $^{5}$. Particularmente, los productos ganaderos (principalmente carne, lana y cuero), hacia mediados del siglo XX inician un fuerte descenso en su participación dentro de las exportaciones totales del país (Azcuy Ameghino, 2007). A partir de la década de 1990, la profundización de un nuevo paradigma socioproductivo implicó intensas transformaciones no sólo socioeconómicas, sino también ambientales y políticas (Gras y Hernández, 2009). En los últimos años, en el municipio se han ido desarrollando procesos de intensificación de la producción ganadera, "[...] estimulados también por la reasignación de espacios productivos impuesta por la 'sojización"' (Azcuy Ameghino, 2007: 212); como así también de incremento de la superficie destinada a la agricultura en su extremo este y oeste (Balda, 2010) ${ }^{6}$.

Imagen 1. Mapa localización Tapalqué en Pcia. Imagen 2. Mapa localidades Partido de Tapalqué,. de Buenos Aires Pcia. de Buenos Aires.

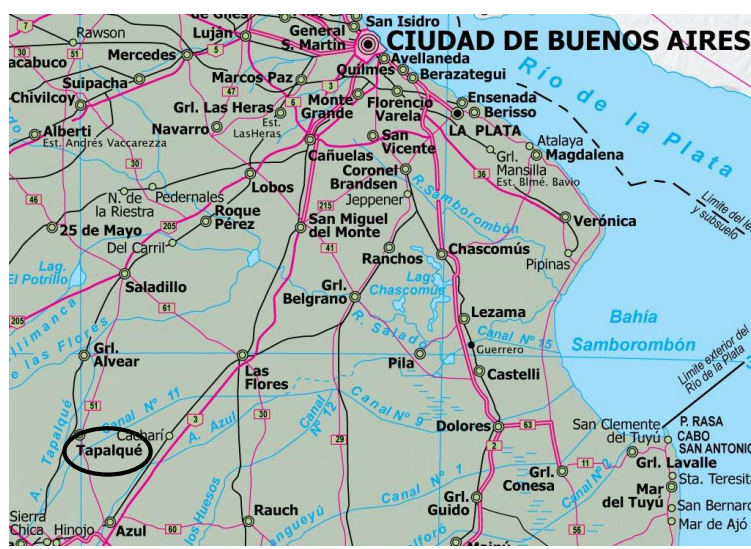

Fuente: Elaboración propia en base a Instituto Geográfico Nacional, s/f.

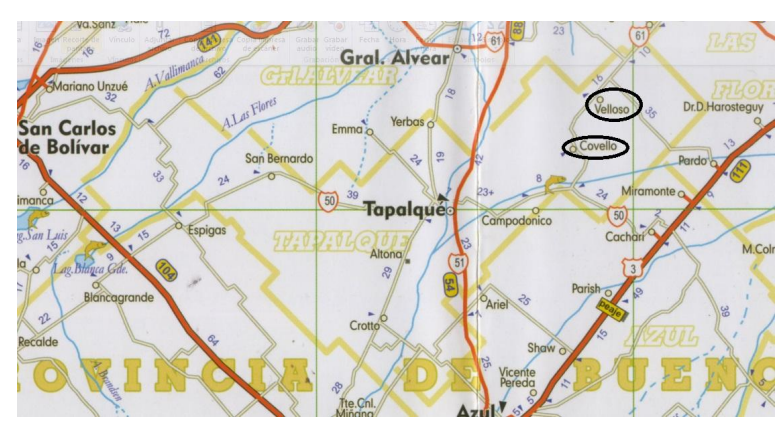

Fuente: Elaboración propia en base a Ministerio de Turismo Buenos Aires, $s / f$.

5 En 1831, la declaración de Tapalqué como cantón militar, da inicio al proceso - que culmina hacia fines del siglo XIX- de incorporación definitiva de sus territorios y pobladores al Estado Nacional, conforme su integración al sistema capitalista internacional, en tanto país productor de bienes agropecuarios. El Partido de Tapalqué fue creado por decreto del gobernador Juan Manuel de Rosas el 25 de diciembre de 1839 . El 7 de noviembre de 1863 se funda el pueblo homónimo.

$6 \quad$ Allí se localizan los mayores porcentajes de suelos con aptitud agrícola del municipio, que en su totalidad no supera el 7\% (Balda, 2010; Valicenti, 2007 en Balda, 2010). 


\section{Papeles de Trabajo $N^{\circ} 28$ - Diciembre 2014 - ISSN 1852-4508 \\ Centro de Estudios Interdisciplinarios en Etnolingüística y Antropología Socio-Cultural}

Particularmente, la región noreste del municipio ${ }^{7}$ tuvo una ocupación distintiva del territorio. Ya desde fines del siglo XIX y principios del XX presentaba diferencias significativas en los patrones de distribución de la tierra, concentrándose allí no sólo un mayor número de explotaciones sino también de menor extensión comparativamente con el resto del Partido. En 1927, se inauguran dos estaciones del Ferrocarril Provincial de Buenos Aires (FPBA) ${ }^{8}$ que conectan directamente estos territorios $-\mathrm{y}$ sus productos y pobladores- con el puerto y la localidad de La Plata y la ciudad de Avellaneda donde funcionaban el Mercado Central de Frutos ${ }^{9}$ y el Mercado de Hacienda de Avellaneda ${ }^{10}$. La trascendencia de la presencia del FPBA en la zona (Aurand, 2013b), no sólo facilitó el intercambio señalado; sino que a medida que se fundaban las estaciones de ferrocarril se fueron configurando diversas localidades, escuelas y parajes rurales; conformándose también, directa e indirectamente, en una importante fuente de empleo asalariado no agrario; al tiempo que dinamizó el mercado de tierras circundantes.

Para mediados del siglo XX, se asentaba allí una numerosa población, con la presencia de productores familiares ganaderos que arrendaban $-\mathrm{y}$ en algunos casos lograron adquirir en propiedadfundamentalmente "campos chicos" pero también "campos medianos". Hacia 1947, 7.230 (68\%) de los 10.646 habitantes del municipio (DNSE, 1947), residían "en el campo"11; el 47,75\% de las 957 EAPs (DNSE, 1947) del Partido se encontraban bajo el régimen de arrendamiento $^{12}$; $y$, significativamente, el 56,95\% (DNSE, 1947) de la superficie total arrendada del municipio pertenecía al segmento "campos chicos".

Existía entre estos productores una amplia diversificación de actividades económicas orientadas al mercado pero también para el autoconsumo donde resultaba fundamental el trabajo de la mano de obra familiar, entre ellas: ganadería ovina extensiva; ganadería bovina extensiva; ganadería aviar extensiva (pollos, pavos y huevos); ganadería porcina; agricultura (algunas pocas hectáreas de maíz utilizado como suplementación para ganado aviar y porcino, y en el caso de explotaciones de mayor superficie, girasol y lino -para su comercialización- y avena -como forrajera y/o venta-); pesca; horticultura; producción láctea (Aurand, 2013b). Asimismo, entre los productores familiares que explotaban "campos chicos" era frecuente el asalaramiento de algunos de sus integrantes (tanto mujeres como hombres) en "campos medianos" y "estancias grandes" de la zona como así también en otras actividades no agrarias; además, en el caso de los hombres, se efectuaban migraciones estacionales laborales (Aurand, 2013b) rurales-rurales. Por lo que se conformaron como proveedores de mano de obra, disponible y barata, dentro de la región pero además para otras zonas agroproductivas de la provincia de Buenos Aires como así también de La Pampa y Río Negro.

\section{Políticas públicas, resistencias, fin del predomino ovino y éxodo rural}

Durante la década de 1960, el despliegue de diversas políticas públicas transformaron profundamente

7 Según las divisiones político-administrativas actuales, quedaría comprendido por el cuartel III y IV de dicha jurisdicción.

8 El FPBA tuvo su origen con la inauguración en 1912 del Ferrocarril Provincial de La Plata a Meridiano V. En el Partido de Tapalqué contaba con tres estaciones: Velloso (ex-“San Andrés”), Covello (ex-“El Bañado") -ramal Beguerie-Azul- y Eufemio Uballes -ramal a Olavarría-. Las dos primeras localizadas, dentro de la división político-administrativa del municipio, en el cuartel III y IV, respectivamente.

$9 \quad$ En el Mercado Central de Frutos se almacenaban principalmente lanas y cueros (vacunos y ovinos) con destino a la exportación (Newland, 2012). Inaugurado en 1887, hacia mediados del siglo XX su actividad comienza a decaer. En 1964 cierra y en 1967 el edificio finalmente fue demolido (Newland, 2012).

10 En el Mercado de Lanares se comercializaba ganado ovino en pie. Fue habilitado en 1890; cesa sus actividades en 1963 y es demolido en 1966.

11 Para esta investigación, se recuperó el indicador sociodemográfico “en el campo" propuesto por Balsa (2006), ya que permite diferenciar la población rural que habita/ba en "campo abierto" (categoría censal "población rural dispersa"), de aquella que lo hace/ía en las pequeñas localidades rurales de menos de 2.000 habitantes (categoría censal "población rural agrupada") (Balsa, 2006: 81).

12 Teniendo en cuenta exclusivamente a los "arrendatarios" sin ningún otro tipo de combinación de régimen legal de tenencia de la tierra. 


\section{Papeles de Trabajo $N^{\circ} 28$ - Diciembre 2014 - ISSN 1852-4508 \\ Centro de Estudios Interdisciplinarios en Etnolingüística y Antropología Socio-Cultural}

las vidas cotidianas de los productores familiares y de los pobladores de las localidades rurales, entre ellas: el cierre del Mercado Central de Frutos y del Mercado de Lanares; la Ley 18.284 (Código Alimentario Argentino); el decreto 4.238 ("Reglamento de Inspección de Productos, Subproductos y Derivados de Origen Animal"). A ello se suma, la crisis en el mercado internacional de lanas, a mediados de 1960, que ocasiona una fuerte disminución de los precios (Llach, 2006). En este contexto, se contrae la producción ovina en el municipio, disminuyendo drásticamente en un $67,42 \%$ el stock ovino en el período 1960-1988, afectando particularmente a los productores de "campos chicos". Del predominio en 1960 del ganado ovino -330.629 cabezas (INDEC, 1960b)- dentro del stock ganadero total del partido, hacia el año 1988, disminuye a 107.715 cabezas (INDEC, 1988); reduciéndose a tan sólo 29.815 cabezas en el 2002 (INDEC, 2002) ${ }^{13}$.

Además de las políticas públicas señaladas previamente, aquí brevemente señalaremos dos más por ser relevantes en la memoria social de los entrevistados al indagar sobre los procesos migratorios: la clausura del ramal "Beguerie-Azul" del FPBA y el decreto-ley 17.253: "[...] en la zona de Covello... más o menos 3 leguas a la redonda [15km] vivían como 70 familias. Eso con el cierre del ferrocarril y los desalojos, se fueron todos [...]" (productor retirado cuartel III).

El ramal del FPBA que atravesaba las localidades de Velloso y Covello se cierra en 1961, en el marco de una serie de políticas públicas desplegadas para enfrentar las dificultades económicas que atravesaba el gobierno de Frondizi. Esta medida fue resistida largamente por los pobladores, quienes intervinieron activamente en pos de su rehabilitación ${ }^{14}$ :

"[la clausura del ramal] [...] traería aparejado la desconcentración de todos esos grupos humanos y el obligado éxodo hacia los grandes centros urbanos, haciendo mayormente graves los problemas que ello crea [...] en infinidad de casos y ante las autoridades correspondientes de todos los gobiernos anteriores, se han efectuado innúmeras gestiones y se han puesto de manifiesto concretamente, los perjuicios que esa medida traería aparejados" (El camino, 1968: 8) ${ }^{15}$.

Sin embargo, el FPBA no sólo no se rehabilitó sino que en la década de $1970^{16}$ se levantaron sus rieles, y se desmantelaron gran parte de sus edificios; por lo que las vías de comunicación en esta zona quedaron limitadas a los caminos de tierra, dificultando su transitabilidad, especialmente en períodos de precipitaciones como así también restringiendo la comercialización de sus productos.

Hacia fines de la década de 1960, como han señalado Barsky y Gelman, luego de sucesivas prórrogas, “(...) culmina el proceso de desaparición legal de las protecciones a los arrendatarios que desde 1942 se acogían a las mismas" (Barsky y Gelman, 2009: 401). La sanción en marzo de 1967 del decreto-ley 17.253, elocuentemente denominada por los pobladores de la zona "ley de desalojo", “(...) disolvió las Cámaras de Arrendamientos y Aparcerías Rurales y culminó definitivamente con las prórrogas de los contratos de arrendamientos vigentes, poniendo con ello fin a la denominada 'emergencia agraria" (Blanco, 2007: 36). Ciertamente, como sostiene Blanco, se puede considerar el retiro de la función reguladora del Estado en el mercado de tierras (Blanco, 2007) como una de las variables que

13 Como se señaló previamente, hay que advertir que durante la realización del CNA 2002, parte del territorio del municipio se encontraba inundado (La Nación, 2001); por lo cual sólo fueron registradas 270.895,4 ha $(64,9 \%)$ de las aproximadamente 417.200 ha de superficie agraria total del Partido.

14 Cabe destacar que otros actores sociales también resistieron tales políticas, como fue el caso de los trabajadores ferroviarios, quienes realizaron huelgas prolongadas.

15 Extracto de uno de los petitorios donde vecinos de la localidad de Covello exhortaban, en 1968, su reanudación a las autoridades de la entonces empresa Ferrocarriles Argentinos -anteriormente denominada Empresa de Ferrocarriles del Estado Argentino (EFEA), bajo la cual había quedado integrado el ex-FPBA tras su nacionalización- al tiempo que advertían las consecuencias que tendría la clausura definitiva del ramal entre los pobladores de la zona.

16 El resto de los ramales del FPBA continuaron en funcionamiento. El servicio de pasajeros fue clausurado en julio de 1977 (durante los primeros años de la última Dictadura Cívico Militar de 1976-1983) aunque el de carga siguió operando hasta la década de 1980. Actualmente, algunos sectores del terraplén donde anteriormente yacían las vías del FPBA conforman, parte de un camino de tierra que conecta, entre otras, las localidades de Velloso y Covello. 


\section{Papeles de Trabajo $N^{\circ} 28$ - Diciembre 2014 - ISSN 1852-4508 \\ Centro de Estudios Interdisciplinarios en Etnolingüística y Antropología Socio-Cultural}

intervinieron en el proceso migratorio de algunos productores familiares de la zona, al poner en jaque su acceso al uso de la tierra fundamentalmente entre quienes producían en "campos chicos" y "campos medianos". En este sentido, para el período 1960-1969, como se ha señalado en un trabajo anterior, descienden estrepitosamente la superficie y el número de explotaciones en arrendamiento (Aurand 2013b).

El impacto de tales políticas en las vidas cotidianas de los pobladores, sumado a la liberación de mano de obra -tanto por la transformación de los usos de la tierra debido al pasaje del predominio de producción ganadera ovina a bovina como así también al proceso de mecanización agrícola que afectaron especialmente a quienes realizaban migraciones laborales estacionales (rural-rural)-; el inicio del proceso de intensificación de la producción avícola y la posibilidad de obtener salarios más altos en los centros urbanos (Slutzky, 1968), fueron algunos de los factores que estimularon los procesos migratorios ruales-urbanos en la zona.

Para fines del período 1960-1980 la población rural del municipio había disminuido estrepitosa y diferencialmente de la siguiente manera: $56,57 \%$ de los pobladores residentes "en el campo"; $59,21 \%$ en Velloso ${ }^{17}$ y -en menor proporción- $21,68 \%$ en Crotto. Sin embargo, y como parte del mismo proceso, la ciudad de Tapalqué incrementó su población en un 43,48\% (ver cuadro 1).

\section{Trayectorias y estrategias migratorias familiares}

Ahora bien, ¿cuáles fueron las trayectorias migratorias? La salida del "campo" no se tradujo en itinerarios migratorios rurales-rurales sino rurales-urbanos: "[...] la gente se tuvo que ir del campo, ya no queda nadie; se fue a la ciudad o a los pueblos [...]" (productor retirado cuartel III). Por lo general, las trayectorias familiares migratorias no han sido unilineales. En este sentido, los primeros itinerarios migratorios de las familias tuvieron como destino localidades urbanas de diversa concentración poblacional de la región, a saber cabeceras de Partidos de la región ganadera de cría extensiva, como Tapalqué, Azul, Olavarría o Las Flores, o bien, localidades intermedias como ser Cacharí (Partido de Azul), y en menor medida hacia la capital provincial ${ }^{18}$ : "Y... la mayoría se fue a Azul, Olavarría, Tapalqué, Cachari, a donde había algún familiar...Más a Olavarría [...]" (ex-poblador cuartel III); "Muchos se fueron a La Plata. Mi mamá se fue a Tapalqué porque la familia de ella era de ahi" (expobladora cuartel III).

Recuperando la regionalización de la provincia de Buenos Aires propuesta por Slutzky $(1968)^{19}$, se pueden observar durante el período 1960-2010 (ver cuadro 1), al menos dos cuestiones para la región ganadera de cría extensiva: a) la población total tuvo un incremento del 37,07\%; mientras que en 1960 era de 326.424 habitantes (INDEC, 1960a), hacia 2010 alcanzaba 447.495 pobladores (INDEC, 2010); b) un fuerte proceso de urbanización: mientras que en 1960 la población urbana representaba el $46,29 \%$ del total de la población y el restante $53,71 \%$ residía en áreas rurales, para 2010 el $87,88 \%$ de la totalidad de la población de la región habitaba en áreas urbanas, disminuyendo a $12,22 \%$ en sus áreas rurales.

Cuadro 1. Total población rural y urbana Región ganadería de cría extensiva ${ }^{20} 1960$ y 2010.

17 En 1970, su población había descendido a 239 habitantes (INDEC, 1970).

18 A modo de hipótesis, parte de los ex-trabajadores del FPBA de la zona migraron en una primera instancia hacia La Plata, con la expectativa de su reincorporación en el ferrocarril.

19 En base a tipos de producción para aquellos partidos cuya producción se orientaba hacia 1960 predominantemente a la ganadería de cría: Ayacucho; Azul; Castelli; Dolores; Gral. Alvear; Gral. Belgrano; Gral. Guido; Gral. La Madrid; Gral. Lavalle; Gral. Madariaga; Benito Juárez; Laprida; Las Flores; Maipú; Mar Chiquita; Olavarría; Pila; Rauch; Saladillo; Tapalqué; Tordillo (Slutzky, 1968).

$20 \quad$ Basado en la propuesta de Slutzky, 1968. 


\begin{tabular}{|l|r|r|r|r|r|r|r|r|r|r|}
\cline { 2 - 9 } \multicolumn{1}{c|}{} & \multicolumn{4}{c|}{1960} & \multicolumn{4}{c|}{$\mathbf{2 0 1 0}$} \\
\cline { 2 - 10 } \multicolumn{1}{c|}{ urbana } & porcentaje & \multicolumn{1}{c|}{ rural } & porcentaje & \multicolumn{1}{c|}{ TOTAL } & urbana & porcentaje & \multicolumn{1}{c|}{ rural } & porcentaje & \multicolumn{1}{c|}{ TOTAL } \\
\hline Total País & 14.758 .341 & 73,75 & 5.252 .198 & 26,25 & 20.010 .539 & 36.514 .216 & 91,02 & 3.602 .880 & 8,98 & 40.117 .096 \\
\hline Total Pcia de Bs. As. & 5.883 .995 & 86,96 & 882.113 & 13,04 & 6.766 .108 & 5.151 .595 & 95,68 & 232.520 & 4,32 & 5.384 .115 \\
\hline Total región ganadería de cría & 198.449 & 60,79 & 127.975 & 39,21 & 326.424 & 392.826 & 87,78 & 54.669 & 12,22 & 447.495 \\
\hline
\end{tabular}

Fuente: Elaboración propia en base a INDEC, 1960a; INDEC, 2010.

No obstante, si desagregamos los datos, se puede constatar que el aumento poblacional fue sumamente diferencial, concentrándose en dos núcleos urbanos de la región: Olavarría y Azul, en tanto se fueron conformando como prestadoras de diversos servicios, principalmente en las áreas de salud y educación (terciaria y universitaria), pero también como importantes centros demandantes de mano de obra (industrias frigoríficas, textiles, mineras, entre otras): "[...] en Azul, había frigorificos, mataderos... estaba sudatex [industria textil sudamtex]. Después todo eso cerró" (productora retirada cuartel III) ${ }^{21}$. Sin embargo, y retomando la perspectiva teórica señalada en las primeras páginas, interesa también abordar aquellas motivaciones personales que intervinieron en los procesos migratorios. Se debe tener en cuenta que, como ha señalado Balsa (2006), entre las décadas de 1970 y 1990 la disminución de los ingresos netos por unidad de superficie fue un factor que impactó fuertemente en las unidades más pequeñas, pero también el incremento de las necesidades de consumo: "Una familia requería cada vez más hectáreas para hacer frente a sus necesidades de consumo, por cierto, también crecientes en la medida en que los productores iban internalizando las pautas de consumo de la clase media urbana" (Balsa, 2006: 245). En este sentido, la posibilidad de escolarización secundaria para los hijos de aquellos productores y pobladores rurales que aún permanecían en el campo (en tanto parte de sus nuevas aspiraciones sociales) surge como uno de los factores principales que, en muchos casos y de acuerdo a los relatos, impulsaron los procesos migratorios de la familia hacia localidades urbanas: "Nos tuvimos que ir del campo porque no nos cerraban las cuentas. Con lo que vendíamos de animales no nos alcanzaba para llevar y traer a los chicos a la escuela [secundaria] a Cacharí, por eso nos tuvimos que mudar al pueblo" (productora familiar retirada cuartel III); "Yo hace años que no estoy allá [Velloso]. Vine a los 13 años para estudiar y después me quedé acá [Cacharí]" (ex-poblador Velloso). En este sentido, los entrevistados destacan un "cambio de mentalidad" (productor retirado cuartel III) intergeneracional en relación a la relevancia de la escolarización secundaria.

Si bien, -en algunos casos- en un principio se intentó mantener la producción "en el campo" y la residencia en la ciudad, esto resultaba muy costoso; por lo que hubo quienes terminaron optando por el abandono de la producción" : "Pensé que iba poder ir y venir al campo, pero no. No alcanzaba. Así que acá adelante abrí el local" (productor familiar retirado cuartel III). Pero también, debido a la fuerte disminución poblacional en la zona, se habían transformado ciertas pautas de sociabilidad: "[...] no volvería al campo ni aunque tuviese las mismas comodidades que en el pueblo. En el pueblo salgo y puedo hablar con cualquiera; en el campo no hay con quien hablar" (productor retirado cuartel III). Sin embargo, en una segunda trayectoria migratoria, algunos de los hijos de estos primeros migrantes rurales-urbanos (que se instalaron en las ciudades de la región) inician una nueva migración (ya en este caso urbana-urbana) hacia centros urbanos del AMBA, principalmente hacia La Plata ${ }^{23}$, dependiendo de la clase social a la que pertenecen, ya sea por razones laborales y/o de estudios universitarios. Sumamente interesantes, resultan las diversas percepciones sobre la migración hacia las

21 Hacia mediados del siglo XX la ciudad de Azul, como sostiene Recci, se había conformado en "[...] una verdadera 'ciudad industrial' formada por un denso tejido industrial a través de encadenamientos agroindustriales y comerciales [...]" (Recci, 2013: 11). A fines de 1960 y principios de la década de 1970, el sector industrial, se había constituido en un importante mercado laboral ocupando aproximadamente 2.000 empleados (Recci, 2013). Muchas de estas industrias cierran en las décadas de 1970 y 1980; mientras que aquellas que lograron permanecer, al profundizarse las políticas neoliberales durante la década de 1990, inician procesos de ajuste y reconversión, expulsando a casi más de la mitad de sus trabajadores (Recci, 2013).

22 El retiro de los productores de la producción de sus explotaciones, ha sido a través de la venta de las explotaciones familiares, o bien mayoritariamente, se han orientado al arrendamiento parcial o total.

23 También, existen casos de migraciones internacionales. 


\section{Papeles de Trabajo $N^{\circ} 28$ - Diciembre 2014 - ISSN 1852-4508 \\ Centro de Estudios Interdisciplinarios en Etnolingüística y Antropología Socio-Cultural}

grandes urbes como vehiculizadora y "garante" de movilidad socioeconómica ascendente. Significativamente, es frecuente una diferenciación entre aquellos jóvenes que al finalizar sus estudios secundarios continúan viviendo en las localidades (y no quieren o no pueden migrar) y aquellos que emigran; asociándose mayormente a los primeros con una connotación negativa: "no tienen ambición". En el mismo sentido, quienes retornan pero no lograron cumplir con el ideario de ascenso socioeconómico. Contrariamente, gozan de gran prestigio social y reconocimiento en sus ámbitos de origen quienes migran y ascienden socialmente (independientemente de si inician o no, un proceso migratorio de retorno).

\section{Migraciones, mercado laboral, edad y género.}

En los últimos años, el Estado -en sus diferentes niveles- ha desplegado diversas políticas a través de una serie de obras de infraestructura y de políticas sociales en el ámbito rural del municipio tendientes a revertir el éxodo rural en los poblados, tales como: reapertura de escuelas primarias en parajes rurales; electrificación rural en Crotto y Velloso ${ }^{24}$; pavimentación de calles, construcción de viviendas e instalación de agua potable en Crotto; construcción y apertura de escuelas secundarias ${ }^{25}$ en Crotto y Velloso; creación de CAPS (Centros de Atención Primaria de la Salud), el Centro de Educación Agropecuaria $^{26}$; muchos de los cuales se constituyeron en fuentes de empleo no sólo para los habitantes locales sino también para pobladores de la ciudad cabecera. Aunque, estas medidas han logrado revertir -en parte- el proceso de despoblamiento en las localidades rurales, no han impactado de igual manera "en el campo", donde muy lentamente continúa el éxodo.

La localidad de Velloso, aunque se vio favorecida por la electrificación y por la apertura de una escuela secundaria, políticas consideradas muy positivamente entre sus pobladores, presenta algunas diferencias significativas con respecto a Crotto ${ }^{27}$ : "Cuando nos enteramos que iba a venir la luz pensamos que iba a haber más gente y mejorar pero mirá, no pasó nada. No es lo mismo que en Crotto [...] Porque en Crotto aumentó la población y acá no. Crotto progresó y nosotros no" (joven de Velloso).

Si bien, al analizar los datos censales (ver cuadro 2), la población en Velloso aumentó un 18,69\% en el período intercensal 2001-2010 $0^{28}$, se observa, al examinar la variación intercensal para el período 19602010 una marcada disminución del 64,02\% de su población.

Si comparamos con la localidad de Crotto (ver cuadro 2), no sólo se aprecia un incremento de habitantes mayor al de Velloso para el período intercensal 2001-2010 del 29,30\% sino que al analizar el período 1960-2010 su población no sólo no disminuyó sino que creció un 9,90\%. Por lo que entendido en estos términos, se advierte una marcada diferenciación entre ambas localidades. Asimismo, el "progeso" de Crotto es considerado para algunos pobladores vellosenses, en términos de otras obras de infraestructura realizadas por el Estado (en sus diferentes niveles) tales como pavimentación, provisión de agua potable, construcción de viviendas; que en algunos casos estarían en proyecto para la localidad de Velloso pero que aún no se han concretado ${ }^{29}$.

$24 \quad 11$ de junio de 2010.

25 La existencia de escuelas secundarias en los pueblos rurales reviste suma importancia, como bien lo destaca Ratier, ya que “(...) significa detener el éxodo educativo que termina arrastrando familias enteras hacia los centros urbanos" (Ratier, 2003: 249).

26 Inaugurado en mayo de 2010.

27 Crotto y Velloso se localizan, por camino de tierra, a $29 \mathrm{~km}$ (SO) y $58 \mathrm{~km}$ (NE) respectivamente, de la ciudad cabecera de partido.

28 Según cálculos propios del CAPS, su población se habría visto incrementada luego de la instalación del tendido eléctrico en el poblado (se debe tener en cuenta que los datos del CN 2010 fueron relevados en octubre de 2010 y teniendo en cuenta que la inauguración de la electrificación se realizó en junio del mismo año, los datos estadísticos del censo no permiten dar cuenta de las transformaciones ocurridas a posteriori).

29 En el caso del agua potable, si bien en junio de 2011, se firmó el proyecto por el cual se otorgaría agua potable a la localidad de Velloso a través del Plan Cuidar del Servicio Provincial de Agua Potable y Saneamiento Rural -(SPAR), dependiente del Gobierno de la Provincia de Buenos Aires- aún resta su concreción, por lo que el abastecimiento entre sus pobladores es por agua de pozo. 
Cuadro 2. Total población y variaciones intercensales (absolutas y relativas) Tapalqué, localidades rurales y “en el campo" para el Partido de Tapalqué, Pcia. de Bs.As. 1960-2010.

\begin{tabular}{|c|c|c|c|c|c|c|c|c|c|c|c|c|c|}
\hline & \multirow{2}{*}{$\begin{array}{c}\text { CENSO } \\
\text { DE } 1960\end{array}$} & \multirow{2}{*}{$\begin{array}{c}\text { CENSO } \\
\text { DE } 1980\end{array}$} & \multicolumn{2}{|c|}{\begin{tabular}{c|} 
VARIACIÓN \\
INTERCENSAL 1960- \\
1980 \\
\end{tabular}} & \multirow{2}{*}{$\begin{array}{l}\text { CENSO } \\
\text { DE } 1991\end{array}$} & \multicolumn{2}{|c|}{\begin{tabular}{c|} 
VARIACIÓN \\
INTERCENSAL 1980- \\
1991 \\
\end{tabular}} & \multirow{2}{*}{$\begin{array}{l}\text { CENSO } \\
\text { DE } 2001\end{array}$} & \multicolumn{2}{|c|}{\begin{tabular}{|c|} 
VARIACIÓN \\
INTERCENSAL 1991- \\
2001 \\
\end{tabular}} & \multirow{2}{*}{$\begin{array}{c}\text { CENSO } \\
\text { DE } 2010\end{array}$} & \multicolumn{2}{|c|}{$\begin{array}{c}\text { VARIACIÓN } \\
\text { INTERCENSAL 2001- } \\
2010 \\
\end{array}$} \\
\hline & & & Absoluta & $\begin{array}{c}\text { Relativa } \\
(\%)\end{array}$ & & Absoluta & $\begin{array}{c}\text { Relativa } \\
(\%)\end{array}$ & & Absoluta & $\begin{array}{c}\text { Relativa } \\
\text { (\%) }\end{array}$ & & Absoluta & $\begin{array}{c}\text { Relativa } \\
(\%)\end{array}$ \\
\hline TAPALQUÉ & 3.733 & 5.356 & 1.623 & 43,48 & 5.045 & -311 & $-5,81$ & 6.605 & 1.560 & 30,92 & 7444 & 839 & 12,70 \\
\hline CROTTO & 226 & 177 & -49 & $-21,68$ & 153 & -24 & $-13,56$ & 191 & 38 & 24,84 & 247 & 56 & 29,32 \\
\hline VELLOSO & 353 & 144 & -209 & $-59,21$ & 119 & -25 & $-17,36$ & 107 & -12 & $-10,08$ & 127 & 20 & 18,69 \\
\hline "En el campo" & 4.978 & 2.162 & -2.816 & $-56,57$ & 2.797 & 635 & 29,37 & 1.393 & -1.404 & $-50,20$ & 1360 & -33 & $-2,37$ \\
\hline TOTAL & 9.290 & 7.839 & -1.451 & $-15,62$ & 8.114 & 275 & 3,51 & 8.296 & 182 & 2,24 & 9.178 & 882 & 10,63 \\
\hline
\end{tabular}

Fuente: Elaboración propia en base a INDEC, 1960a; INDEC, 1980; INDEC, 1991; INDEC, 2001; INDEC, 2010.

Si bien, la educación secundaria en las localidades rurales, ha postergado la edad en que migran los jóvenes (y sus familias), una vez finalizada dicha instancia educativa, la falta de empleo constituye una de las principales razones esgrimidas para el éxodo de este rango etario como así también de su grupo familiar (ver gráfico 1): “[...] sí, pero eso no basta [la educación secundaria en Velloso]. Porque no hay trabajo. No hay futuro acá. A mi me encantaría poder quedarme acá pero no hay trabajo, así que sé que hoy no, pero mañana o el año que viene me voy a tener que ir" (joven del cuartel IV).

Gráfico 1. Pirámide poblacional de Velloso, año 2010, Pdo. de Tapalqué, Provincia de Buenos Aires.

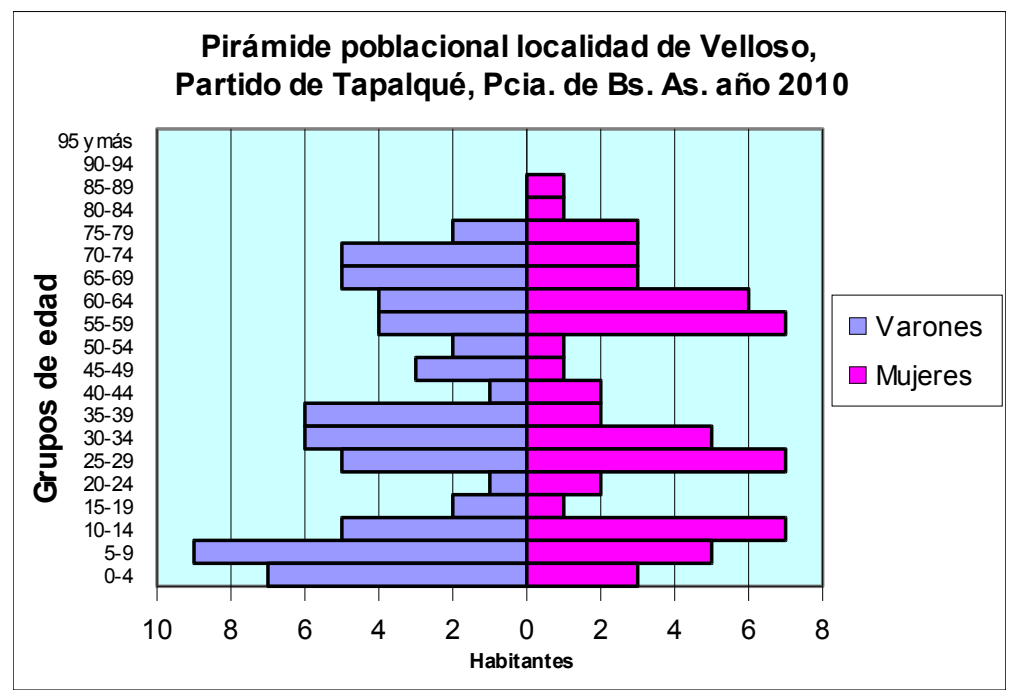

Fuente: elaboración propia en base a INDEC, 2010.

Como ha señalado Comas D'Argemir: "Es la construcción social de la diferencia como desigualdad lo que funciona como factor estructurante en la división del trabajo" (Comas D'Argemir, 2009: 170). En este sentido, clase, etnia, género y edad constituyen relaciones sociales determinantes que estructuran diferencialmente el acceso (o no) al mercado de trabajo. La edad, como se ha señalado, constituye un factor estructurante por lo que una vez finalizado los estudios secundarios los jóvenes deben migrar. Pero también el género, ya que si bien algunos de los empleos estatales en la localidad rural son cubiertos por mujeres; el mercado laboral "en el campo" se encuentra fuertemente concentrado por los hombres (si bien, en casos donde se contratan trabajadores rurales permanentes con sus familias, algunas de sus mujeres realizan trabajo doméstico en la residencia del "patrón"; su empleo siempre queda supeditado a la previa contratación de su pareja) por lo que ser "joven y mujer" constituiría un doble factor que dificulta la inserción en este mercado laboral (ver gráfico 2). Aquí también se articula con una de las estrategias, señalada por Villafañe para su análisis en Olavarría, a través de la cual las familias aseguran la continuidad de la producción en la explotación familiar al proyectar "(...) en sus 
hijos varones su futuro y su progreso" (Villafañe, 2007: 197).

Gráfico 2. Pirámide poblacional "en el campo"30, año 2010, Pdo. de Tapalqué, Provincia de Buenos Aires.

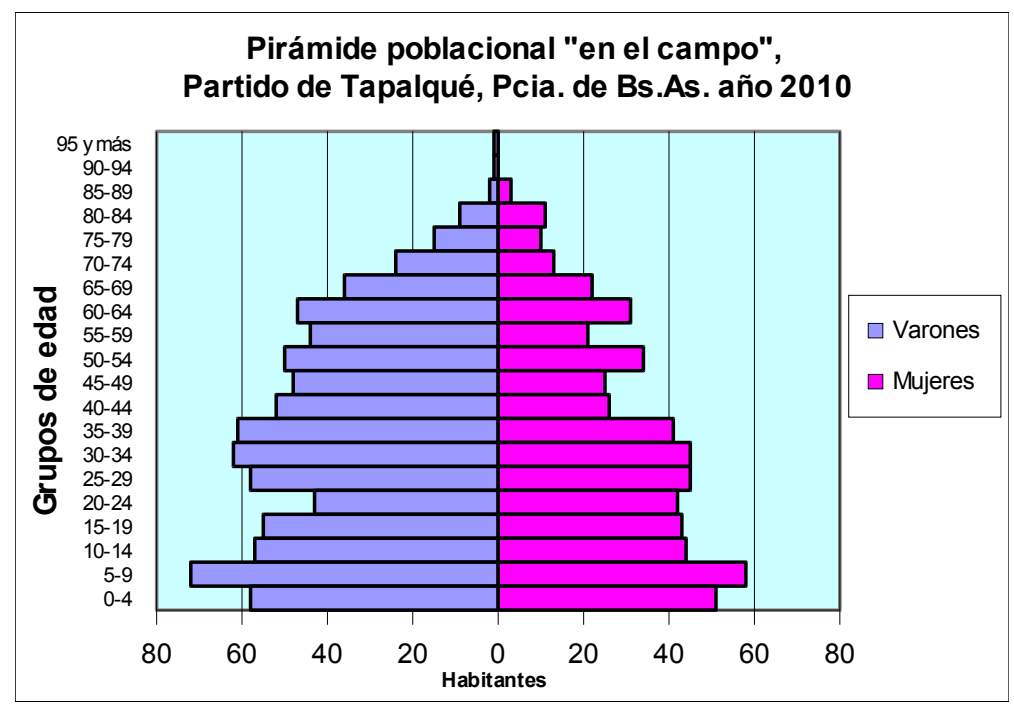

Fuente: elaboración propia en base a INDEC, 2010.

Pero, ¿qué hay de quiénes migraron hacia urbes cercanas? Como tan bien ha advertido Ratier al abordar otras localidades medianas del Centro de la Provincia de Buenos Aires, “(...) con un importante hinterland ${ }^{31}$ agroganadero, las redes sociales enlazan campo y ciudad en una trama única que es menester considerar en el análisis social" (Ratier, 2009: 30). De esta manera, si bien se ha trasladado la residencia familiar hacia las urbes, muchos de sus integrantes -preferentemente masculinos- continúan vinculados a actividades agropecuarias "en el campo"; en algunos casos de su propiedad, en otros tantos ajenos (ya sea como empleados rurales, arrendatarios o contratistas). En este sentido, hay quienes se conformaron/conforman en mano de obra disponible y barata para realizar tareas agrícola-ganaderas puntuales o permanentes (tanto en ámbitos rurales como urbanos ${ }^{32}$ ). Como así también el caso (cada vez más frecuente) de quienes "van y vienen todos los días al campo". Asimismo, algunos migrantes se convirtieron en contratistas agrícolas (brindando servicios de siembra, fumigación y cosecha); comerciantes vinculados a la producción agrícola-ganadera; prestadores de servicios agroprofesionales (preferentemente veterinarios); como así también transportistas (de hacienda y de cosechas).

\section{Retornos y vínculos con el "pago"}

Como se ha señalado previamente, los migrantes han mantenido, y mantienen, fuertes vínculos (sociales, económicos, laborales, políticos, afectivos y simbólicos) con su ámbito de origen ${ }^{33}$. En la zona abordada, estos no son recientes sino que remiten a los primeros años posteriores al inicio de los procesos migratorios de la década de 1960. En este sentido, en 1965, el regreso por un fin de semana para un evento deportivo ${ }^{34}$ de un contingente de migrantes vellosenses, residentes en la localidad de

$30 \quad$ Basado en la propuesta de Balsa, 2006.

31 En cursiva en el original.

32 Sumamente significativos resultan ser los remates ganaderos en las localidades cercanas, donde se contrata mano de obra masculina estacional "[...] para el trabajo en la feria con animales" (productor cuartel III).

33 Existen excelentes trabajos que abordan, en otros municipios del centro de la Pcia. de Bs. As., diversas vinculaciones de familias residentes en ámbitos urbanos con "el campo" (ver Villafañe, 2007; Ratier, 2009).

34 El retorno puntual de aquellos migrantes con mayores destrezas deportivas para los campeonatos de fútbol resultaba una práctica frecuente en la zona; incluso, en algunos casos, sus viajes eran financiados por los 


\section{Papeles de Trabajo $N^{\circ} 28$ - Diciembre 2014 - ISSN 1852-4508 \\ Centro de Estudios Interdisciplinarios en Etnolingüística y Antropología Socio-Cultural}

La Plata, constituyó un acontecimiento destacado. Resulta sumamente significativa la letra de la "Marcha de los Ex-Vellosenses" entonada durante la jornada, de la cual interesa destacar, al menos tres cuestiones; la pertenencia identitaria, la selectividad etaria de quienes migraron y el vínculo afectivo con el poblado:

"Aqui estamos Velloso nuevamente. Tus calles volveremos a cruzar. Y si lejos de tí nos hemos ido. Jamás te pudimos olvidar [...] Dichosos nos volvemos a abrazar. A padres, hermanos y amigos. Cariños imposibles de borrar. La distancia no existe en el recuerdo. Inolvidable pueblo de Velloso. Y surgen a tu vista nuevamente. De nuestra infancia los recuerdos más dichosos" (El camino, 1965: 2).

Pero estos vínculos también brindaron, y brindan, múltiples contraprestaciones, como alojamiento en las casas de migrantes (por ejemplo, cuando ante diversas razones, como ser de salud, deben viajar a la capital provincial); o bien asistencia (alimentos, ropa, etc.) durante las terribles inundaciones de 1980. Particularmente, estas relaciones sociales permitieron diversificar las estrategias económicas para aquellos grupos domésticos que permanecían "en el campo", a fin de garantizar su continuidad. En este sentido, un migrante del cuartel III residente en La Plata proveía, a través de sus relaciones de amistad platenses, "cazadores" a un grupo doméstico que habitaba y explotaba un "campo chico" durante las décadas de 1970 y 1980 . Si bien la familia no cobraba dinero por el alojamiento en la casa rural, sí por la provisión de chacinados elaborados por el grupo doméstico.

Hoy en día, estas relaciones sociales también resultan estratégicas para garantizar la continuidad de los productores familiares, de modo que, por ejemplo, un familiar emigrado hace décadas del cuartel III, residente en la localidad de Azul, constituye un nexo fundamental para la comercialización de pollos, pavos y huevos de sus familiares que producen en una explotación familiar en la zona de origen. Se debe destacar que este canal de comercialización constituye una "ventaja" comparativa ya que en Azul se obtienen mejores precios que en otras localidades cercanas, por ejemplo, Cacharí o Tapalqué; o que la compra por mayoristas o minoristas directamente "en el campo".

En aquellos casos en los cuales una parcialidad del grupo doméstico ha quedado a cargo de la explotación, ha resultado fundamental para su permanencia el aporte económico realizado por los miembros que emigraron: "[...] no se mantiene sólo con el campo, hoy en día nadie puede vivir con pocas hectáreas solamente del campo. Sigue ahi [productor cuartel III 100 ha en propiedad y 100 ha arrendadas a un familiar] porque tiene a su hijo que trabaja en el exterior y le gira dinero, sino no podría estar viviendo en el campo" (productor retirado cuartel III).

Pero también los diversos eventos escolares y festividades, conectan de una manera particular a migrantes y a quienes permanecen en sus lugares de origen ${ }^{35}$. Los migrantes, se mantienen informados a través de las relaciones de parentesco, vecindad o bien, últimamente, a través de redes sociales tales como facebook, las cuales constituyen un importante medio de socialización de "novedades" del pago y de una manera de estar "conectados". Asimismo, resulta relevante, su participación y colaboración económica para los preparativos de muchos de estos eventos: "[...] estamos recaudando fondos para la fiesta porque son muchos gastos [...] [dos ex-residentes] se ofrecieron a pagar todo lo que es tarjetería" (integrante cooperadora escuela cuartel III) ${ }^{36}$.

Finalmente, otra de las múltiples modalidades, que ya ha sido descripta en otro trabajo (Aurand, 2013a) lo constituyen las visitas que realizan familiares y amigos (quienes migraron hacia los centros urbanos de la región o del AMBA) a quienes residen tanto en poblados rurales como en establecimientos productivos "en el campo", durante los recesos estivales e invernales, como así

almaceneros quienes veían incrementados sus espectadores (y ventas) al asegurarse la presencia de alguna "figura" deportiva destacada (sobre la relevancia del fútbol en las áreas rurales, ver Ratier, 2009).

35 La trascendencia de tales eventos ha sido analizado por Villafañe y Ratier para otras localidades del Centro de la Provincia de Buenos Aires (Villafañe, 2007; Ratier, 2003; Ratier, 2009).

36 También, de quienes producen y residen en la zona, ya sea a través de la prestación de mano de obra o bien, la donación de terneros o corderos (preferentemente se apela a aquellos productores que tienen vínculos "previos" con la zona). 
también durante los fines de semanas "largos"37.

En los últimos años, se asiste a diversos procesos migratorios "de retorno" selectivo: en contados casos en los ámbitos rurales y fundamentalmente, hacia alguna de las localidades urbanas más pobladas regionalmente tales como Olavarría o Azul, pero así también a Cacharí o Tapalqué. En estos casos, algunos jóvenes han retornado a los pueblos, y logran insertarse en el mercado laboral del lugar de origen o en alguna localidad cercana ${ }^{38}$; destacándose al igual como tan bien ha caracterizado Alicia Villafañe para localidades del municipio de Olavarría “(...) el afecto de los jóvenes por su localidad. La valoración que realizan, tanto ellos como sus padres, de la vida tranquila, sin problemas de delincuencia (...)" (Villafañe, 2000: 95). Abrazando estos imaginarios sociales, en los últimos años jubilados procedentes del AMBA (algunos de ellos dentro de procesos migratorios "de retorno") decidieron migrar hacia localidades como Cacharí o Tapalqué.

\section{Reflexiones finales}

A lo largo de este trabajo se ha realizado una aproximación a la problemática planteada, sin pretender dar una visión acabada, ya que al ser parte de una investigación en curso se halla en permanente reformulación, construcción y contrastación.

Durante el abordaje de esta cuestión tan compleja, se ha enfatizado el dinamismo y la multidimensionalidad de los procesos migratorios. Asimismo, se ha destacado el rol del Estado en estos procesos migratorios a través de sus políticas públicas en general y en materia de transporte, sanidad e higiene, agropecuaria y de arrendamientos en particular. Pero también se consideraron, las estrategias y motivaciones personales que permitieron comprender la selectividad de los migrantes.

Si bien las trayectorias migratorias no han sido unilineales, se ha expuesto una tendencia de una primera migración rural-urbana hacia centros urbanos de la región ganadera de cría extensiva. Y posteriormente, una segunda migración (de los miembros más jóvenes), ya en este caso urbana-urbana hacia ciudades más alejadas.

Asimismo, se han evidenciado aquellas políticas públicas que intentan revertir los procesos migratorios rurales-urbanos, destacando sus alcances, incidencias diferenciales al interior del municipio, y sus limitaciones. Si bien la posibilidad de acceso a la educación secundaria ha constituido un mecanismo eficaz que "posterga" las edades en que los jóvenes (y mayormente también su grupo familiar) deben migrar; posteriormente no logran insertarse en un mercado de trabajo cada vez más restringido en "el campo" producto de la profundización de un nuevo paradigma socioproductivo pero también estructurado diferencial y desigualmente por relaciones sociales de edad, género y clase.

A su vez, se señalaron algunos de los vínculos sociales, económicos, laborales, afectivos y simbólicos que los migrantes han mantenido, y mantienen con su ámbito de origen; señalando la importancia que tales relaciones sociales han tenido, y tienen, para asegurar la continuidad de quienes permanecieron en el lugar de origen. Finalmente, se destacaron diversos procesos migratorios "de retorno" selectivo.

En este complejo devenir, los pobladores de los ámbitos rurales despliegan múltiples estrategias de resistencia a fin de permanecer en el "pago"; siendo la migración la última -y menos deseada- de sus opciones.

\section{Bibliografía}

ARIZPE, L. (1976): "Migración indígena problemas analíticos" - Nueva Antropología - 5 Asociación Nueva Antropología A. C. - Distrito Federal (págs 63-89).

AURAND, M. (2013a): "Procesos de patrimonialización y turistificación en ámbitos rurales y urbanos en el Partido de Tapalqué (Provincia de Buenos Aires): reflexiones preliminares" - IV Jornadas de Antropología Social del Centro - UNICEN.

37 Esta práctica también ha sido descripta por Villafañe para el municipio de Olavarría (Villafañe, 2007) y por Ratier para los partidos de Azul y Olavarría (2003).

38 Ya sea porque finalizan sus estudios terciarios o universitarios, y/o bien porque cuentan con algún "contacto" para obtener algún empleo público o privado. 
AURAND, M. (2013b): “'Los paisanos estamos en el pueblo y los pueblerinos en el campo': Continuidades, transformaciones y rupturas en las estrategias productivas de productores familiares ganaderos" - VII Jornadas de Investigación en Antropología Social - FFyL-UBA.

AZCUY AMEGHINO, E. (2007): La carne vacuna argentina: Historia, actualidad y problemas de una agroindustria tradicional - Imago Mundi - Buenos Aires.

BALSA, J. (2006): El desvanecimiento del mundo chacarero: transformaciones sociales en la agricultura bonaerense: 1937-1988 - Editorial Universidad Nacional de Quilmes - Bernal.

BARSKY, O. y GELMAN, J. (2009): Historia del Agro Argentino. Desde la conquista hasta fines del Siglo XX-Editorial Sudamericana - Buenos Aires.

BLANCO, M. (2007): "La tierra como bien social: los arrendamientos rurales y la discusión de un viejo problema" - Páginas. Revista digital de la escuela de historia - 1 - FHYA-UNR - (págs. 71-94).

COMAS D'ARGEMIR, D. (1983): "Ganaderos, boyeros, pastores, obreros: estrategias económicas en el Pirineo de Aragón" - Temas de antropología aragonesa - 1 - Instituto Aragonés de Antropología Huesca (págs 63-83).

COMAS D'ARGEMIR, D. (2009): “Trabajo, economía sumergida y género. La atención a la dependencia" en Economía informal y perspectiva de género en contextos de trabajo - Téllez Infantes, A. y Martínez Guirao, J. E. (EDS) - Icaria. Barcelona.

DEVOTO, F. (1992): "Las cadenas migratorias italianas: algunas reflexiones a la luz del caso argentino" en Movimientos migratorios: historiografía y problemas - Devoto, F. - CEAL. Buenos Aires.

GRAS, C. y HERNÁNDEZ, V. (2009): "El fenómeno sojero en perspectiva: dimensiones productivas, sociales y simbólicas de la globalización agrorrural en la Argentina" en La Argentina rural: de la agricultura familiar a los agronegocios - Gras, C. y Hernández, V. (COORD) - Editorial Biblos. Buenos Aires.

LLACH, L. (2006): Argentina y el mercado mundial de sus productos, 1920-1976 - CEPAL - Buenos Aires.

NEWLAND, C. (2012). "Mercado Mammoth: infraestructura y comercio de productos agropecuarios a través de una empresa argentina 1887-1916"-RIIM-.

PEDONE, C. (2010): “Cadenas y redes migratorias: una propuesta metodológica para el análisis diacrónico-temporal de los procesos migratorios" - Empiria - 19 - UNED - Madrid (págs 101-132).

PORTES, A. (2007): "Migración y desarrollo: una revisión conceptual de la evidencia" en Migración y desarrollo: perspectivas desde el sur - Castles, S. y Delgado Wise, R. (COORD) - Miguel Ángel Porrúa. México.

RATIER, H. E. (2003): "Estrategias regresivas en la Pampa globalizada y las fronteras entre lo rural y lo urbano" - Runa. Archivo para las ciencias del hombre - 24 - ICA-FFyL-UBA - Buenos Aires (págs 233-255).

RATIER, H. E. (2009): Poblados bonaerenses: vida y milagros - Editorial La Colmena - Buenos 
Aires.

RECCI, K. V. (2013): "Reestructuración industrial y territorio: efectos desiguales en la ciudad de Azul (Provincia de Buenos Aires, Argentina), 1990-2008" - Revista Geografia y Sistemas de Información Geográfica - 5 - GESIG-UNLu - Luján (págs 1 -31).

SLUTZKY, D. (1968): "Aspectos sociales del desarrollo rural en la pampa húmeda Argentina" Desarrollo Económico - 29 - IDES - Buenos Aires (págs 95-135).

VIDAL, V. B. (2007). "Censos Agropecuarios Nacionales: Un análisis metodológico necesario" - IX Jornadas de Investigación del Centro de Investigaciones Geográficas y del Departamento de Geografia $\quad-\quad$ La $\quad$ Plata. Disponible http://www.fuentesmemoria.fahce.unlp.edu.ar/trab_eventos/ev.726/ev.726.pdf

VILLAFAÑE, A. (2000): "Las formas familiares de producción en el agro, características y persistencia en el contexto local. El caso de la pampa bonaerense" - Intersecciones en Antropología 1 - Universidad Nacional del Centro de la Provincia de Buenos Aires - Olavarría (págs 87-100).

VILLAFAÑE, A. (2007): "Formas familiares, producción y reproducción en la Pampa argentina" Etnia - 48 - Instituto de Investigaciones Antropológicas y Museo Etnográfico Municipal Dámaso Arce - Olavarría (págs 187-207).

\section{Fuentes}

BALDA, S. (2010): Utilización de procesos participativos en productores ganaderos. El caso del grupo San Gabriel. Trabajo final especialización en Desarrollo Rural, Facultad de Agronomía-UBA.

DNSE (Dirección Nacional del Servicio Estadístico) (1947): IV Censo General de la Nación. Tomo I. Censo de Población.

INSITUTO GEOGRÁFICO NACIONAL (s/f): Mapa de la Provincia de Buenos Aires.

INDEC (1960a): Censo Nacional de Población 1960.

INDEC (1960b): Censo Nacional Agropecuario 1960.

INDEC (1970): Censo Nacional de Población, Familias y Viviendas. 1970.

INDEC (1980): Censo Nacional de Población, Hogares y Vivienda 1980.

INDEC (1988): Censo Nacional Agropecuario 1988.

INDEC (2001): Censo Nacional de Población, Hogares y Vivienda 2001.

INDEC (2002): Censo Nacional Agropecuario 2002.

INDEC (2010): Censo Nacional de Población, Hogares y Viviendas 2010. http://www.censo2010.indec.gov.ar/ consultado el 8 de mayo de 2014.

LA NACIÓN. (2001): Más de 3.000 evacuados en la Provincia. En: http://www.lanacion.com.ar/344924-mas-de-3000-evacuados-en-la-provincia consultado el 10 de septiembre de 2013. 
Centro de Estudios Interdisciplinarios en Etnolingüística y Antropología Socio-Cultural

EL CAMINO. (1965): Marcha de los Ex Vellosenses. 4 de noviembre. Año IX.

EL CAMINO. (1968): De Covello. Un memorial. 31 de octubre. Año XII.

MINISTERIO TURISMO BUENOS AIRES (s/f): Mapa de Rutas. Turismo Buenos Aires. La Provincia.

\section{Agradecimientos}

Al Dr. Sebastián Valverde por sus valiosos comentarios que permitieron una versión mejorada de este escrito. A mi colega y compañera de equipo Laura Weiss por su gentil y desinteresada colaboración. A Carlos Balderrama y Marcelo Andrada del Archivo del Museo Nacional Ferroviario, un muy afectuoso agradecimiento por su permanente colaboración brindada a lo largo de esta investigación. A Pablo y a Marcelo, por su buena predisposición y amabilidad al proporcionarme los archivos del semanario "El camino". A los pobladores y ex-pobladores del noreste de Tapalqué, un muy afectuoso agradecimiento por su enorme amabilidad, sin ellos esta investigación no sería posible. 